
D:\Nsurg|Vol. 23, No. 4, Oct. - Dec., 2019\Nsurg-8.Doc
Fig. 1-2 Color
(A)
P. $277-282 \quad$ III

ORIGINAL ARTICLE

\title{
Outcome of Microsurgical Clipping of Ruptured Anterior Circulation Aneurysms
}

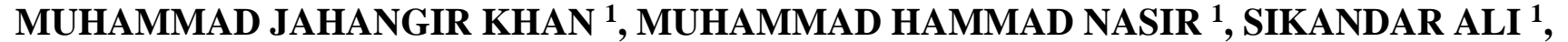 \\ SARFRAZ KHAN ${ }^{\mathbf{2}}$, MUHAMMAD WAQAS ${ }^{\mathbf{1}}$, ZUBAIR AHMED KHAN ${ }^{\mathbf{1}}$ \\ ${ }^{1}$ Department of Neurosurgery, Postgraduate Medical Institute, Lahore General Hospital, Lahore \\ ${ }^{2}$ Khyber Medical University, Kohat Institute of Medical Sciences, Kohat \\ DOI: https://doi.org/10.36552/pjns.v23i4.383
}

\begin{abstract}
Objective: The objective of the study was to analyze the operative outcome of microsurgical clipping in Ruptured Anterior Circulation Aneurysms.

Materials and Methods: Twenty patients with Ruptured Anterior Circulation aneurysms were treated with surgical clipping. All the patients were evaluated pre-operatively according to Hunt \& Hess and WFNS grading scales. Patients with grade I, II, and III were operated. All the aneurysms were clipped through Pterional approach under General anesthesia and Yasargil Aneurysm clips of appropriate sizes were used in each patient. Outcome was analyzed according to Glasgow Outcome Scale at the end of six months of follow up in each patient.
\end{abstract}

Results: In this series of twenty cases, the mean patient age was 49 years. Lesion location included, the ACA/A. Com 55\% $(n=11)$, the Middle Cerebral artery 25\% $(n=5)$, . Com 15\% $(n=3)$, Ophthalmic artery 5\% $(n=1)$. Sex distribution, female 55\% $(n=11)$ and male $45 \%(n=9)$. Per-operative complications, rupture of aneurysm $20 \%(n=4)$, and damage to perforating branches of MCA 5\% $(n=1)$. Postoperatively Meningitis occurred in $5 \%(n=1)$, wound infection in 10\% $(n=2)$, Hydrocephalus $10 \%(n=2)$, Hemiparesis $10 \%(n=2)$, and death in $15 \%(n=3) .70 \%(n=14)$ patients were in Glasgow outcome scale 4 and $5,10 \%(n=2)$ in GOS 3, while 5\% $(n=1)$ were in GOS 2 at six months of Follow-up. $15 \%(n=3)$ mortality was noted.

Conclusions: Surgical clipping still is the most efficient treatment of Ruptured Anterior Circulation aneurysm at the beginning of the new millennium. Anterior Communicating Artery is the commonest location of aneurysms. Major determinants of outcome are Hunt \& Hess, WFNS grades on admission and the age of the patient.

Keywords: Aneurysms, complications, outcome, subarachnoid hemorrhage.

\section{INTRODUCTION}

An aneurysm is a disease of vessels caused by abnormal dilatation and located at the site of weakness in the elastic layer of the artery. Cerebral aneurysms represent saccular dilatations that appear more frequently at bifurcation of intracranial cerebral vessels. ${ }^{1}$ Autopsy studies have estimated that 2 percent of the entire population harbor cerebral aneurysm. An aneurysm will rupture in less than 1 percent of the population and will be the cause of death in 0.5 percent. Aneurysmal subarachnoid hemorrhage
(SAH), occurring secondary to rupture of an aneurysm in the cerebral circulation, is a relatively common problem, with an incidence of 12 to 15 per 100,000 population per year. The maximum incidence of ruptured aneurysms is between the ages of $40 \& 60$ years with women preponderant. Predisposing factors for rupture of an aneurysm are hypertension, use of tobacco, abuse of alcohol, pregnancy, and strenuous activity. ${ }^{1-3}$

The prognosis of patients with an untreated saccular aneurysm that has ruptured is grim: 60 to 70 
percent mortality and morbidity at 6 months after hemorrhage. Although, a major decline in mortality and morbidity brought about through improvement in diagnosis and management of patient with cerebral aneurysms has occurred over the past 30 year, the mortality and morbidity associated with aneurysmal SAH continue to be significant. Approximately, onequarter to one-third of patients with SAH die before reaching the hospital and the mortality of the remaining patients approaches 30 to 50 percent. Among patients reaching neurological center alive, poor outcome (as defined by mortality and major neurologic morbidity) is now mainly due to an episode of aneurysm re-bleeding and delayed ischemic neurologic deficits (vasospasm).Together, these complications after primary aneurysmal SAH are responsible for more than 50 percent of the mortality and morbidity from SAH. Aneurysmal re-bleeding can be effectively eliminated by successfully obliterating the aneurysm from the cerebral circulation with modern surgical or endovascular technique. Important strides have been made in the surgical management of these patients and a significant majority of these patients with cerebral aneurysms can be successfully treated with surgery. ${ }^{1,3}$

Although the etiology of cerebral aneurysms is originally congenital, acquired factors also play a role, including degenerative changes, thinning of media, inflammation, atherosclerosis, hypertension and hemodynamic stress. Some heredity conditions are associated with intracranial aneurysms, such as the Ehlers-Danlos syndrome, Coarctation of aorta, polycystic kidney disease, arteriovenous malformations, Fibromuscular dysplasia and Sickle cell disease. Aneurysm can also be caused although rare, by trauma, infection, and arteriosclerosis due to damage to the arterial wall.,4 Approximately 85 percent of intracranial aneurysms occur in the anterior circulation. More than a third arise from Anterior communicating artery complex, internal carotid artery is the next most common site. Middle cerebral artery account for about 20 percent and usually occurs at the bifurcation or trifurcation. ${ }^{3}$

A clipping of a ruptured aneurysm is the definitive method for lesion obliteration and prevention of rebleeding. Furthermore, after clipping, subsequent vasospasm can be treated aggressively and more effectively. The "gold standard" of treatment is to exclude the aneurysm from circulation by placing a metal clip across its neck. ${ }^{5}$ The outcome measures used to assess patients with aneurysmal SAH fall into three categories: the clinical condition or functional ability of the patient, the status or the radiographic appearance of the lesion, and patient satisfaction. Increasingly, clinicians recognize that detailed consideration should be given to each of these aspects of outcome. In addition, the outcome should be stratified according to the factors that influence overall morbidity, such as patient age, clinical grade at presentation and size and location of the aneurysm. ${ }^{1}$

\section{MATERIALS AND METHODS}

\section{Study Design}

This descriptive case study was carried out at the department of Neurosurgery, Post Graduate Medical Institute, Lahore General Hospital Lahore and Khyber Medical University, Kohat Institute of Medical Sciences, Kohat from November 2014 to December 2015 for the duration of one year. A total of 20 patients were included in this study of both genders (male and female) and in the age range of 25-70 years.

\section{Inclusion Criteria}

Following patients were included. Patients with Spontaneous Subarachnoid hemorrhage in the area of anterior circulation, seen on the CT scan and confirmed by angiography. Only patients with Hunt \& Hess or WFNS grades I, II and III. Patients with anterior circulation aneurysms presenting with signs and symptoms of space occupying lesions.

\section{Exclusion Criteria}

Patients with Hunt \& Hess or WFNS grades IV and V.

\section{Data Collection}

The patients presented with subarachnoid hemorrhage in Neurosurgical Emergency were assessed and diagnosis of Ruptured Anterior Circulation Aneurysms was picked for study. All the patients were evaluated pre-operatively according to Hunt \& Hess and WFNS grading scales of Subarachnoid hemorrhage. All patients had four vessel angiography by the digital subtraction method. It was performed only in patients with Hunt \& Hess and WFNS grade I, II \& III or when they improved to these grades.

Patients in Grades I, II \& III were operated or until they improved to these grades. All aneurysms were clipped through Pterional approach under General 
Anesthesia and Yasargil Aneurysmal clips of appropriate size was used for clipping in each patient. Data was collected according to the Proforma.

Follow-up was done one month, three months and six months after discharge. At each follow up visit complete CNS examination was performed and positive findings were recorded. Patients who did not reported for follow-up were contacted at their addresses.

\section{Data Analysis}

Data analysis was performed by uses SPSS Version 2.0. Outcome was analyzed according to Glasgow Outcome scale at the end of six months in each patient.

\section{RESULTS}

\section{Gender Distribution}

Twenty patients of Ruptured Anterior Circulation aneurysm were managed with surgical clipping from November 2009 to December 2010.55\% (11/20) patients were female and 45\% (9/20) male.

\section{Age Incidence}

Minimum and maximum age of presentation was 25 and 70 years respectively. The mean age of patients was 48.85 years. Maximum patients, i.e. $30 \%(6 / 20)$ presented during fifth decade. It was followed by $4^{\text {th }}$ decade during which $25 \%(5 / 20)$ patients presented. During the $7^{\text {th }}$ and $6^{\text {th }}$ decades, 20\% (4/20) and $15 \%$ (3/20) patients presented respectively. In $3^{\text {rd }}$ decade, only $10 \%(2 / 20)$ patient presented. No patient was presented during $1^{\text {st }}, 2^{\text {nd }}$, and $8^{\text {th }}$ decades. Patients of good outcome were relatively younger; the mean age at presentation was 49 years.

\section{Clinical Presentation}

All cases presented with sudden severe headache vomiting and need stiffness. Presentation of MCA aneurysms was relatively earlier compared to $\mathrm{P}$ Com and A.Com aneurysms. In this study, 65\% (13/20) patients were presented before 50 years and $35 \%$ (7/20) afterwards.

Female to male ratio in good outcome patients was 4:3. Severely disabled patient was male. Three patients died, two were female and one male. A patient who reached hospital within 24 hours of hemorrhage were $40 \%(8 / 20)$ while $25 \%(5 / 20)$ within $2-5$ days. $20 \%$ $(4 / 20)$ patients reached the hospital from $5^{\text {th }}$ day for 2 weeks, $10 \%(2 / 20)$ patients reached during $3^{\text {rd }}$ week and 5\% (1/20) after 3 weeks.

In this study, $40 \%(8 / 20)$ were hypertensive and $10 \%(2 / 20)$ had a history of diabetes mellitus. $15 \%$ $(3 / 20)$ patients had Ischemic heart disease and $10 \%$ $(2 / 20)$ were smokers. No patient had a family history of aneurysmal subarachnoid hemorrhage or alcohol intake.

Patients admitted in Hunt \& Hess grade I \& II were $45 \%$ (9/20). Patients in Hunt \& Hess grade III and IV were $40 \%(8 / 20)$ and $15 \%(3 / 20)$ respectively.

$60 \%(12 / 20)$ patients were operated in WFNS grade I \& II while $40 \%(8 / 20)$ patients were in WFNS grade III at the time of operation.

In this study, 55\% (11/20) patients had Ruptured A.Com aneurysms. 54.5\% (6/11) patients having A.Com aneurysms were approached through Right pterional approach while $45.5 \%(5 / 11)$ patients were operated from left side. 25\%(5/20) patients had Ruptured MCA aneurysms in which 60\% (3/5) patients had right MCA aneurysms while $40 \%$ (2/5) patients had left Ruptured MCA aneurysm. Pterional craniotomy was done on the side of the aneurysm. All patients had Ruptured MCA aneurysms at the bifurcation of MCA territory. 15\% (3/20) patients had right Ruptured P. Com aneurysms and were operated through right pterional craniotomy. $\mathrm{T}$ ruptured Ophthalmic artery aneurysm was 5\% (1/20) in this series and approached through left pterional craniotomy. Per-operative complications, rupture of aneurysm 20\% ( $\mathrm{n}=4)$, and damage to perforating branches of MCA 5\% $(\mathrm{n}=1)$.

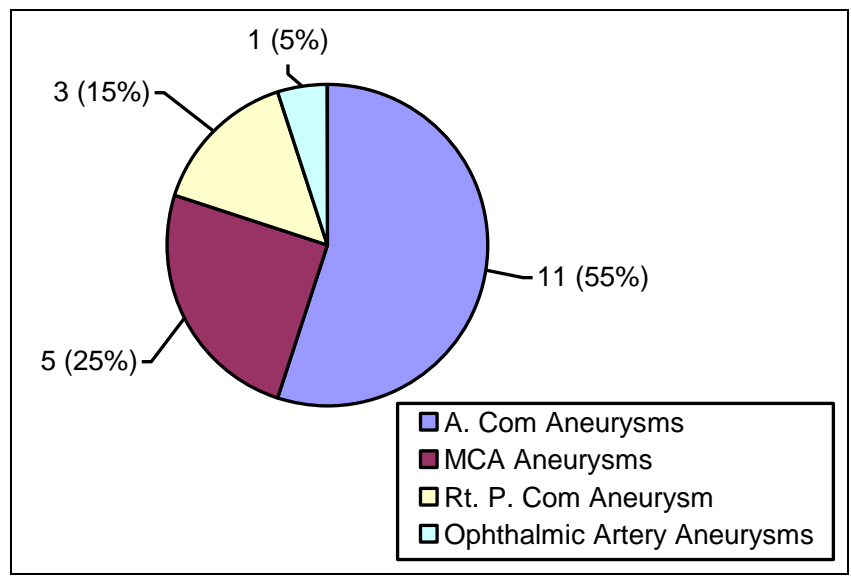

Fig. 1: Distribution of Aneurysms. 


\section{Outcome}

Postoperatively Meningitis occurred in 5\% $(\mathrm{n}=1)$, wound infection in $10 \%(\mathrm{n}=2)$, Hydrocephalus $10 \%$ $(\mathrm{n}=2)$, Hemiparesis $10 \%(\mathrm{n}=2)$, and death in $15 \%$ $(\mathrm{n}=3) .70 \%(\mathrm{n}=14)$ patients were in Glasgow outcome scale 4 and $5,10 \%(n=2)$ in GOS 3, while $5 \%(\mathrm{n}=1)$ were in GOS 2 at six months of Follow-up. $15 \%(\mathrm{n}=3)$ mortality was noted.

\section{DISCUSSION}

In this study, 55\% (11/20) patients had an aneurysm of anterior communicating artery. It was the commonest site of aneurysms. Similar results have been reported in other series. In a multi-centre study, the data was collected from the eight centers performing aneurysm surgery in Pakistan in which anterior communicating artery aneurysms accounts for $50 \%$ and were reported as the commonest of 240 intracranial aneurysms. ${ }^{9}$ In a one-year angiography study of 49 patients at Neuroradiology Department Lahore General Hospital, Lahore, A.Com artery was also reported as the commonest site. ${ }^{11}$ In one study, Sim also reported A Com aneurysm as the commonest and Lee LS as the $2^{\text {nd }}$ commoner anterior circulation aneurysm. ${ }^{12,13}$

Glasgow Outcome Score $4 \& 5$ were present in $91 \%(10 / 11)$ while $9 \%(1 / 11)$ died in our series. Operative mortality i.e. $9 \%$ of A Com aneurysm is comparable with $15 \%$ and $4.9 \%$ reported by Korol et al. and Park SK respectively. The second commoner site for aneurysms was MCA. Twenty-five percent $(5 / 20)$ patients had MCA aneurysms in this series, $20 \%(4 / 20)$ on right and 5\% (1/20) on left side. All patients had aneurysms on MCA bifurcation. Raja et al and Korol et al, reported 19\% (46/240) and 20.4\% of MCA aneurysms in their series which is less as compared to our series. ${ }^{12,14}$

For MCA aneurysms in our study, GOS 5 was found in $40 \%(2 / 5)$ while GOS 3 in $20 \%(1 / 5)$ of patients. $40 \%(2 / 5)$ patients died in this series. Operative mortality for MCA aneurysms was $40 \%$ (2/5). Mortality was higher compared to $11.3 \%$ mortality for patients with pre-operative Hunt \& Hess grade I, II and III as reported by Kinouchi and Mizoi. ${ }^{16}$

Ophthalmic artery aneurysms were present in 5\% $(1 / 20)$ and had a good outcome. Eldridge reported good outcome in $74 \%$ patients of ophthalmic artery aneurysms. ${ }^{17}$

P. Com aneurysms were present in $15 \%(3 / 20)$ patients. Two patients had a good outcome and one became severely disabled. It was reported as the commonest by Salah-ud-Din and second commoner site by Raja. ${ }^{9}, 10$ Good outcome in patients of P. Com aneurysm was reported $86 \%$ by Raja et al while it was $66 \%$ in our study. ${ }^{9}$

In this study the overall good outcome (GOS 4, 5) was $70 \%$. Moderate disability (GOS 3 ) was $10 \%$ and $5 \%$ severe (GOS 2) disability was found. $15 \%$ mortality (GOS 1) was reported in this series. Hunt \& Hess and WFNS grading scales at the time of admission showed strong correlation with the final outcome according to Glasgow outcome scale with $\mathrm{p}$ value 0.001 (i.e. statistically highly significant).

Ogunbgo et al, reported overall favorable outcomes in $83.3 \%$ of patients. ${ }^{6}$ In this study, $85 \%$ (17/20) of patients who had Hunt \& Hess grade I, II \& III on admission had GOS of $5 \& 4$ in $82 \%$ of patients as compared to $88 \%$ in Ogunbgo et al series. ${ }^{6}$

Our $10 \%(2 / 20)$ patients had moderate disability. All patients had this disability before surgery. No patient in this group had progression of its neurological deficit post-operatively. Post-operative moderate disability was reported $20 \%$ by Raja et al. Salah-ud-Din et al reported no patient ending with moderate disability. ${ }^{9,10}$

In this study, 5\% (1/20) became severely disabled. It was reported $10 \%$ and $11 \%$ by Raja et al and Salahud-Din et al. ${ }^{910}$ Severe disability reported by Ogunbgo et al is $4 \% .^{6}$ These results are comparable to our study. Operative mortality was 15\% (3/20) in our study group as compared to Raja IA series in which mortality was $10 \% .^{9}$

Wong et al. reported $13.7 \%$ operative mortality in Hunt \& Hess grade I, II \& III which is comparable to mortality in this study in patients with admission Hunt \& Hess grade I, II \& III. $^{7}$ Also, operative mortality was reported $20 \%$ in patients with pre-operative Hunt and Hess grade I, II and III in Roganovic and Pavlicevic series which is comparable to $15 \%$ mortality rate in our study. ${ }^{8}$ Similarly, $8.6 \%$ mortality was reported by David $\mathrm{G}$ et al in surgical management of giant intracranial aneurysms. ${ }^{18}$ But, Lafuente et al reported $2.6 \%$ mortality in surgical management of ruptured intracranial aneurysms by experienced hands. ${ }^{19}$ Recently, Lehecka et al reported $0.4 \%$ mortality in the microsurgical management of distal cerebral artery aneurysms and concluded that DACA aneurysms surgical management show same outcome as for other aneurysms. ${ }^{20}$ 


\section{CONCLUSION}

It was concluded in our study that Anterior Communicating Artery is the commonest of all aneurysms and surgical clipping is still comparable treatment for Anterior Circulation aneurysms. Major determinants of outcome depend upon the Hunt \& Hess score and WFNS grades on admission and age of the patient.

\section{REFERENCES}

1. Wecht DA, Awwad IA. Subarachnoid Haemorrhage. In: Principle of neurosurgery. $2^{\text {nd }}$ ed. Grossman RG, Loftus CM (ed). Philadelphia: Lippincott-Raven Publishers, 1999: 297-308.

2. Khan NZ, Iqbal Z. Cerbrovascular disease, increasing incidence of primary intra cerebral haemorrage: a preliminary report of 100 cases. Pak J Neurol. 1999; 5: 45-9.

3. Sekhar LN, Heros RC. Origin, growth, and rupture of saccular aneurysms; a review. Neurosurgery, 1988; 8: 248-60.

4. Fayyaz M, Hassan MA, Attique MH. Risk factors and early prognosis in stroke. Ann KE Med Coll. 1999; 5: 12-5.

5. Chicoine MR. Microsurgery and clipping: the gold standard for treatment of intracranial aneurysms. J Neurosurg Anaesthesiol. 2003; 15: 61-3.

6. Ogungbo B, Gregson BA, Blacburn A, Mendelow AD. Newcastle subarachnoid study group. Trends over time in the management of subarachnoid haemorrhage in Newcastle" review of 1609 patients. Br J Neurosurg. 2001; 15: 388-95.

7. Wong SH, Yeo TT, Seow WT, Tan KK, Ong PL. Spontaeous subarachnoid haemorrhage and Outcome. Results from Tan Tock Seng Hospital, Singapore. Singapore Med J. 1999; 40: 463-74.

8. Ruganovic Z, Pavlicevic G. Factors influencing the outcome after the operative treatment of cerebral aneurysm of anterior circulation. Military Medical Academy, Belgrade. Vojnosanit-Pregl. 2002; 59: $463-$ 71.

9. Raja IA, Javaid MA. Aneurysm surgery in Pakistan $5^{\text {th }}$ International Workshop on cerebrovascular surgery $\left(5^{\text {th }}\right.$ IWCVS) March, 3-5 1997, Kyushu University Japan: 131.

\section{Additional Information}

Disclosures: Authors report no conflict of interest.

Ethical Review Board Approval: The study was conformed to the ethical review board requirements.

Human Subjects: Consent was obtained by all patients/participants in this study.

Conflicts of Interest:

In compliance with the ICMJE uniform disclosure form, all authors declare the following:

Financial Relationships: All authors have declared that they have no financial relationships at present or within the previous three years with any organizations that might have an interest in the submitted work.

Other Relationships: All authors have declared that there are no other relationships or activities that could appear to have influenced the submitted work.
10. Salah-ud-Din T, Hussain A, Khurshid M. Management of Intracranial aneurysms, Review of 25 cases of SAH. Pak J Neurol. 1995; 2: 2121-22.

11. Ghani MA, Javaid MA, Rashid U, Ayub A. A study of Intracranial aneurysm. Pak J Neurol. 1996; 2: 48-51.

12. Sim JH. Intracranial aneurysm in Korea. 5th International workshop on cerebrovascular surgery program and abstracts book Fukoka, Japan, 1997: 12930.

13. Lee LS. Aaneurysmal subarachnoid haemorrhage in Taiwan International Workshop on Cerebrovascular Surgery. Program and Abstracts Fukoka, Japan, 1997: 124.

14. Korol AP Sons AS, Klaoupic LE, Chomitskaya TV. Microsurgical results of anterior circulation aneurysms Final programme and abstract book The 4th Asian Ocean International Congress of Skull Base Surgery; Islamabad - Pakistan, 1997: 124.

15. Park SK, Kwon SC, Lee SU, Kwon JD: Surgical management outcome of patients with ruptured anterior communicating artery aneurysms. 5th International workshop on cerebrovascular surgery. Program and abstracts book Fukoka, Japan, 1997: 129.

16. Kinouchi $\mathrm{H}$ and Mizoi K. Aneurysms of middle cerebral artery. The $3^{\text {rd }}$ Asian conference of neurological surgeons: programs \& abstracts. Nagoya, Japan, 2000: 22.

17. Eldridge PR: Anterior circulation aneurysm In: Neurosurgery. Palmer JD (ed). New York; Churchill Livingstone, 1996: 440-46.

18. Ruptured giant intracranial aneurysms part II. A retrospective analysis of timing and outcome of surgical treatment. David G. Piepgras, ViniG. Khurana and Jack P. Whishant. Journal of Neurosurgery, March, 1998.

19. Ruptured intracranial aneurysms: The outcome of surgical treatment of experienced hands in the period prior to the advent of endovascular coiling. J Lafuente, RS Maurice-Williams. J Neurol Neurosurgery Psychiatry, 2003 and outcome analysis of 501 patients. Martin Lehecka, Hanna Lehto, Mika Niemda, SeppoJuvela, Reza Dashti, Timo Koinisto, Antti Ronkainen, Takko Rime, Juha E. Jaaskelainen, Juha A. Hernesnieme. 5 Neurosurgery, Volume 62, March, 2008
20. Distal anterior cerebral artery aneurysms: Treatment 
Address for Correspondence:

Dr. Zubair Ahmed Khan

Department of Neurosurgery, Postgraduate Medical Institute

Lahore General Hospital, Lahore

Email: zooobby890@gmail.com

\begin{tabular}{|c|c|c|c|}
\hline \multicolumn{4}{|c|}{ AUTHORSHIP AND CONTRIBUTION DECLARATION } \\
\hline Sr.\# & Author's Full Name & $\begin{array}{l}\text { Intellectual/Contribution to Paper in Terms } \\
\text { of: }\end{array}$ & \multirow{4}{*}{$\begin{array}{l}\text { Signature by the } \\
\text { author(s) }\end{array}$} \\
\hline 1. & $\begin{array}{l}\text { Muhammad Jahangir Khan } \\
\text { (Main/Principal Author). }\end{array}$ & $\begin{array}{l}\text { 1. Proposed topics and Basic Study Design, } \\
\text { methodology. }\end{array}$ & \\
\hline 2. & $\begin{array}{l}\text { Muhammad Hammad Nasir } \\
\text { (2nd Author) }\end{array}$ & \multirow{4}{*}{$\begin{array}{l}\text { 2. Data collection and calculations } \\
\text { 3. Analysis of data and interpretation of results } \\
\text { etc. } \\
\text { 4. Literature review and writing of discussion } \\
\text { section. } \\
\text { 5. Paper writing, referencing, Data Calculations } \\
\text { and quality insurer }\end{array}$} & \\
\hline 3. & $\begin{array}{l}\text { Sikandar Ali } \\
\text { (3rd Author) }\end{array}$ & & \\
\hline 4. & $\begin{array}{l}\text { Sarfraz Khan } \\
\text { (4th Author) }\end{array}$ & & \\
\hline 5. & $\begin{array}{l}\text { Muhammad Waqas } \\
\text { (5th Author) }\end{array}$ & & \\
\hline 6. & $\begin{array}{l}\text { Zubair Ahmed Khan } \\
\text { (6th Author) }\end{array}$ & $\begin{array}{l}\text { 6. Study Design and methodology, proof } \\
\text { readings. }\end{array}$ & \\
\hline
\end{tabular}

Date of Submission: 07-09-2019

Date of Revision: 10-11-2019

Date of Online Publishing: 25-12-2019

Date of Print: 31-12-2019 